\title{
Information Literacy Compentency Standards for Higher Education
}

\author{
The final version, approved January 2000
}

Prepared by the ACRL Task Force on Information Literacy Competency Standards

\section{Information literacy defined}

Information literacy is a set of abilities requiring individuals to "recognize when information is needed and have the ability to locate, evaluate, and use effectively the neecled information."

Information literacy also is increasingly important in the contemporary environment of rapid technological change and proliferating information resources. Because of the escalating complexity of this environment, individuals are faced with diverse, abundant information choices-in their academic studies, in the workplace, and in their personal lives. Information is available through libraries, community resources, special interest organizations, media, and the Internet-and increasingly, information comes to individuals in unfiltered formats, raising questions about its authenticity, validity, and reliability.

In addition, information is available through multiple media, including graphical, aural, and textual, and these pose new challenges for individuals in evaluating and understanding it. The uncertain quality and expanding quantity of information pose large challenges for society. The sheer abundance of information will not in itself create a more informed citizenry without a complementary cluster of abilities necessary to use information effectively.

Information literacy forms the basis for lifelong learning. It is common to all disciplines, to all learning environments, and to all levels of education. It cnables learners to master content and extend their investigations, become more self-directed, and assume greater control over their own learning. An information literate individual is able to:

- determine the extent of information needed;

- access the needed information effectively and efficiently;

- evaluate information and its sources critically;

- incorporate selected information into one's knowledge base;

- use information effectively to accomplish a specific purpose; and

- understand the economic, legal, and social issues surrounding the use of information, and access and use information ethically and legally.

\section{About the authors}

Members of the task force are Chair Patricia lannuzzi, University of California-Berkeley, e-mail: piannuzz@library.berkeley.edu; Mike Eisenberg, University of Washington; Donald W. Farmer, Kings College; Craig Gibson, George Mason University; Lori A. Goetsch, University of Maryland; Barton Lessin, Wayne State University; Bonnie Gratch Lindauer, City College of San Francisco; Hannelore B. Rader, University of Louisville; Oswald Ratteray, Middle State Commission of Higher Education; and Althea H. Jenkins, ex-officio, ACRL 


\section{Information literacy and information technology}

Information literacy is related to information technology skills, but has broader implications for the individual, the educational system, and for society. Information technology skills enable an individual to use computers, software applications, databases, and other technologies to achieve a wide variety of academic, work-related, and personal goals. Information literate individuals necessarily develop some technology skills.

Information literacy, while showing significant overlap with information technology skills, is a distinct and broader area of competence. Increasingly, information technology skills are interwoven with, and support, information literacy. A 1999 report from the National Research Council promotes the concept of "fluency" with information technology and delineates several distinctions useful in understanding relationships among information literacy, computer literacy, and broader technological competence.

The report notes that "computer literacy" is concerned with rote learning of specific hardware and software applications, while "fluency with technology" focuses on understanding the underlying concepts of technology and applying problem-solving and critical thinking to using technology. The report also discusses differences between information technology fluency and information literacy as it is understood in $\mathrm{K}-12$ and higher education. Among these are information literacy's focus on content, communication, analysis, information searching, and evaluation; whereas information technology "fluency" focuses on a deep understanding of technology and graduated, increasingly skilled use of it. ${ }^{2}$

"Fluency" with information technology may require more intellectual abilities than the rote learning of software and hardware associated with "computer literacy" but the focus is still on the technology itself. Information literacy, on the other hand, is an intellectual framework for understanding, finding, evaluating, and using information-activities that may be accomplished in part by fluency with information technology, in part by sound investigative methods, but most important, through critical discernment and reasoning. Information literacy initiates, sustains, and extends lifelong learning through abilities which may use technologies but are ultimately independent of them.

\section{Information literacy and higher education}

Developing lifelong learners is central to the mission of higher education institutions. By

\section{Developing the Information Literacy Competency Standards}

Recognizing the role of critical thinking in the learning process, in 1998 the ACRL Board established a Task Force on Information Literacy Competency Standards and charged it to develop competency standards in this area for higher education. Through a series of conference calls, meetings, and e-mail discussions, the Task Force prepared a draft "Information Literacy Competency Standards for Higher Education."

The draft was presented at higher education and library meetings and posted on the ACRL Web site in order to solicit feedback. Comments were reviewed by the task force and the standards were revised. In July 1999, Craig Gibson was appointed as a new task force member to work with the task force on the rewrite of the introduction and expansion of the front matter. In
September 1999, Nana Lowell, an assessment consultant from the University of Washington, was contracted to provide feediback about implications for assessment.

These standards were reviewed by the ACRL Standards Committee and approved by the Board of Directors of the Association of College and Research Libraries (ACRL) on January 18, 2000, at the Midwinter Meeting of the American Library Association in San Antonio, Texas.

ACRL seeks endorsement and promulgation of these standards from professional and accreditation associations in higher education. An Information Literacy Standards Implementation Task Force will be charged to promote the use of the standards in higher education. We encourage you to share these with your colleagues and appropriate organizations. 
ensuring that individuals have the intellectual abilities of reasoning and critical thinking, and by helping them construct a framework for learning how to learn, colleges and universities provide the foundation for continued growth throughout their careers, as well as in their roles as informed citizens and members of communities. Information literacy is a key component of, and contributor to, lifelong learning. Information literacy competency extends learning beyond formal classroom settings and provides practice with selfdirected investigations as individuals move into internships, first professional positions, and increasing responsibilities in all arenas of life. Because information literacy augments students' competency with evaluating, managing and using information, it is now considered by several regional and disciplinebased accreditation associations as a key outcome for college students. ${ }^{3}$

For students not on traditional campuses, information resources are often available through networks and other channels, and distributed learning technologies permit teaching and learning to occur when the teacher and the student are not in the same place at the same time. The challenge for those promoting information literacy in clistance education courses is to develop a comparable range of experiences in learning about information resources as are offered on traditional campuses. Information literacy competencies for distance learning students should be comparable to those for "on campus" students.

Incorporating information literacy across curricula, in all programs and services, and throughout the administrative life of the university requires the collaborative efforts of faculty, librarians, and administrators. Through lectures and by leading discussions, faculty establish the context for learning. Faculty also inspire students to explore the unknown, offer guidance on how best to fulfill information needs, and monitor students' progress. Academic librarians coordinate the evaluation and selection of intellectual resources for programs and services; organize and maintain collections and many points of access to information; and provide instruction to students and faculty who seek information. Administrators create opportunities for collaboration and staff development among faculty, librarians, and other professionals who initiate information literacy programs, lead in planning and budgeting for those programs, and provide ongoing resources to sustain them.

\section{Information literacy and pedagogy}

The Boyer Commission Report "Reinventing Undergraduate Education," recommends strategies that require the student to engage actively in the "framing of a significant question or set of questions, the research or creative exploration to find answers, and the communications skills to convey the results ..." Courses structured in such a way create student-centered learning environments where inquiry is the norm, problem solving becomes the focus, and thinking critically is part of the process. Such learning environments require information literacy competencies.

Gaining skills in information literacy multiplies the opportunities for students' self-directed learning as they become engaged in using a wide variety of information sources to expand their knowledge, ask informed questions, and sharpen their critical thinking for still further self-directed learning. Achieving competency in information literacy requires an understanding that this cluster of abilities is not extraneous to the curriculum but is woven into the curriculum's content, structure, and sequence. This curricular integration also affords many possibilities for furthering the influence and impact of such student-centered teaching methods as problembased learning, evidence-based learning, and inquiry learning. Guided by faculty and others in problem-based approaches, students reason about course content at a deeper level than is possible through the exclusive use of lectures and textbooks. To take fullest advantage of problem-based learning, students must often use thinking skills requiring them to become skilled users of information sources in many locations and formats, thereby increasing their responsibility for their own learning.

To obtain the information they seek for their investigations, individuals have many options. One is to utilize an information retrieval system, such as may be found in a library or in databases accessible by computer from any location. Another option is to select an appropriate investigative method for 
olserving phenomena clirectly. For example, physicians, archaeologists, and astronomers frequently depend upon physical examination to detect the presence of particular phenomena. In addition, mathematicians, chemists, and physicists often utilize technologies such as statistical software or simulators to create artificial conditions in which to observe and analyze the interaction of phenomena. As stuclents progress through their undergraduate years and graduate programs, they need to have repeated opportunities for seeking, evaluating, and managing information gathered from multiple sources and discipline-specific research methods.

\section{Use of the standards}

"Information Literacy Competency Standards for Higher Education" provides a framework for assessing the information literate indiviclual. It also extends the work of the American Association of School Librarians Task Force on Information Literacy Standards, therely providing higher education an opportunity to articulate its information literacy competencies with those of $\mathrm{K}-12$ so that a continuum of expectations develops for students at all levels. The competencies presented here outline the process by which faculty, librarians, and others pinpoint specific indicators that identify a student as information literate.

Students also will find the competencies useful, because they provide students with a framework for gaining control over how they interact with information in their environment. It will help to sensitize them to the need to develop a metacognitive approach to learning, making them conscious of the explicit actions required for gathering, analyzing, and using information. All students are expected to demonstrate all of the competencies described in this document, but not everyone will demonstrate them to the same level of proficiency or at the same speed.

Furthermore, some disciplines may place greater emphasis on the mastery of competencies at certain points in the process, and therefore certain competencies would receive greater weight than others in any rubric for measurement. Many of the competencies are likely to be performed recursively, in that the reflective and evaluative aspects included within each standard will require the student to return to an earlier point in the process, revise the information-seeking approach, and repeat the same steps.

To implement the standards fully, an institution should first review its mission and educational goals to determine how information literacy would improve learning and enhance the institution's effectiveness. To facilitate acceptance of the concept, faculty and staff development is also crucial.

\section{Information literacy and assessment}

In the following competencies, there are five standards and twenty-two performance indicators. The standards focus upon the needs of students in higher education at all levels. The standards also list a range of outcomes for assessing student progress toward information literacy. These outcomes serve as guidelines for faculty, librarians, and others in developing local methods for measuring student learning in the context of an institution's unique mission. In addition to assessing all students' basic information literacy skills, faculty and librarians should also work together to develop assessment instruments and strategies in the context of particular disciplines, as information literacy manifests itself in the specific understanding of the knowledge creation, scholarly activity, and publication processes found in those disciplines.

In implementing these standards, institutions need to recognize that different levels of thinking skills are associated with various learning outcomes - and therefore different instruments or methods are essential to assess those outcomes. For example, both "higher order" and "lower order" thinking skills, based on Bloom's "Taxonomy of Educational Objectives," are evident throughout the outcomes detailed in this document. It is strongly suggested that assessment methods appropriate to the thinking skills associated with each outcome be identified as an integral part of the institution's implementation plan.

For example, the following outcomes illustrate higher order and lower order thinking skills:

Louer Order thinking skill:

Outcome 2.2.a. Identifies keywords, synonyms, and related terms for the information needed. 
Higher Order thinking skill:

Outcome 3.3.b. Extends initial synthesis, when possible, to a higher level of abstraction to construct new hypotheses that may required additional information.

Faculty, librarians, and others will find that discussing assessment methods collabor-atively is a very productive exercise in planning a systematic, comprehen- sive information literacy program. This assessment program should reach all students, pinpoint areas for further program development, and consolidate learning goals already achieved.

It also should make explicit to the institution's constituencies how information literacy contributes to producing educated students and citizens.

\section{Standards, performance indicators, and outcomes}

\section{Standard one}

The information literate student determines the nature and extent of the information needed.

\section{Performance Indicators}

1. The information literate student defines and articulates the need for information.

Outcomes include:

a. confers with instructors and participates in class discussions, peer workgroups, and electronic discussions to identify a research topic, or other information need;

b. develops a thesis statement and formulates questions based on the information need;

c. explores general information sources to increase familiarity with the topic:

d. defines or modifies the information need to achieve a manageable focus;

e. identifies key concepts and terms that describe the information need; and

f. recognizes that existing information can be combined with original thought, experimentation, and/or analysis to produce new information.

2. The information literate student identifies a variety of types and formats of potential sources for information.

Outcomes include:

a. knows how information is formally and informally produced, organized, and disseminated;

b. recognizes that knowledge can be organized into disciplines that influence the way information is accessed;

c. identifies the value and differences of potential resources in a variety of formats (e.g., multimedia, database, Web) site, data set, audio/visual, book);

d. identifies the purpose and audience of potential resources (e.g., popular vs. scholarly, current vs. historical);

e. differentiates between primary and secondary sources, recognizing how their use and importance vary with each discipline; and

f. realizes that information may need to be constructed with raw data from primary sources.

3. The information literate student considers the costs and benefits of acquiring the needed information.

Outcomes include:

a. determines the availability of needed information and makes decisions on broaclening the information-seeking process beyond local resources (e.g., interlibrary loan; using resources at other locations; obtaining images, videos, text, or sound)

b. considers the feasibility of acquiring a new language or skill (e.g., foreign or discipline-based) in order to gather needed information and to understand its context; and

c. defines a realistic overall plan and timeline to acquire the needed information.

4. The information literate student reevaluates the nature and extent of the information need.

Outcomes include:

a. reviews the initial information need to clarify, revise, or refine the question; and

b. describes criteria used to make information decisions and choices. 


\section{Standard two}

The information literate student accesses needed information effectively and efficiently.

\section{Performance Indicators}

1. The information literate student selects the most appropriate investigative methods or information retrieval systems for accessing the needed information.

\section{Outcomes include:}

a. identifies appropriate investigative methods (e.g., laboratory experiment, simulation, fieldwork);

b. investigates benefits and applicability of various investigative methods;

c. investigates the scope, content, and organization of information retrieval systems; and

d. selects efficient and effective approaches for accessing the information needed from the investigative method or information retrieval system.

2. The information literate student constructs and implements effectively designed search strategies.

\section{Outcomes include:}

a. develops a research plan appropriate to the investigative method;

b. identifies keywords, synonyms and related terms for the information needed;

c. selects controlled vocabulary specific to the discipline or information retrieval source;

d. constructs a search strategy using appropriate commands for the information retrieval system selected (e.g., Boolean operators, truncation, and proximity for search engines; internal organizers such as indexes for books);

e. implements the search strategy in various information retrieval systems using different user interfaces and search engines, with different command languages, protocols, and search parameters; and

f. implements the search using investigative protocols appropriate to the discipline.

3. The information literate student retrieves information online or in person using a variety of methods.

\section{Outcomes include:}

a. uses various search systems to retrieve information in a variety of formats; b. Uses various classification schemes and other systems (e.g., call number systems or indexes) to locate information resources within the library or to identify specific sites for physical exploration;

c. Uses specialized online or in-person services available at the institution to retrieve information needed (e.g., interlibrary loan/ document delivery, professional associations, institutional research offices, community resources, experts, and practitioners); and

d. uses surveys, letters, interviews, and other forms of inquiry to retrieve primary information.

4. The information literate student refines the search strategy if necessary.

\section{Outcomes include:}

a. assesses the quantity, quality, and relevance of the search results to determine whether alternative information retrieval systems or investigative methods should be utilized;

b. identifies gaps in the information retrieved and determines if the search strategy should be revised; and

c. repeats the search using the revised strategy as necessary.

5. The information literate student extracts, records, and manages the information and its sources.

\section{Outcomes include:}

a. selects among various technologies the most appropriate one for the task of extracting the needed information (e.g., copy/paste software functions, photocopier, scanner, audio/visual equipment, or exploratory instruments);

b. creates a system for organizing the information;

c. differentiates between the types of sources cited and understands the elements and correct syntax of a citation for a wide range of resources;

d. records all pertinent citation information for future reference; and

e. uses various technologies to manage the information selected and organized.

\section{Standard three}

The information literate student evaluates information and its sources critically and 
incorporates selected information into his or her knowledge base and value system.

\section{Performance indicators}

1. The information literate student summarizes the main ideas to be extracted from the information gathered.

\section{Outcomes include.}

a. reads the text and selects main ideas;

b. restates textual concepts in his/her own words and selects data accurately; and

c. identifies verbatim material that can be then appropriately quoted.

2. The information literate student articulates and applies initial criteria for evaluating both the information and its sources.

\section{Outcomes include:}

a. examines and compares information from various sources in order to evaluate reliability, validity, accuracy, authority, timeliness, and point of view or bias;

b. analyzes the structure and logic of supporting arguments or methods;

c. recognizes prejudice, deception, or manipulation; and

d. recognizes the cultural, physical, or other context within which the information was created and understands the impact of context on interpreting the information.

3. The information literate student synthesizes main ideas to construct new concepts.

\section{Outcomes include}

a. recognizes interrelationships among concepts and combines them into potentially useful primary statements with supporting evidence;

b. extends initial synthesis, when possible, at a higher level of abstraction to construct new hypotheses that may require additional information; and

c. utilizes computer and other technologies (e.g., spreadsheets, databases, multimedia, and audio or visual equipment) for studying the interaction of ideas and other phenomena.

4. The information literate student compares new knowledge with prior knowledge to determine the value added, contradictions, or other unique characteristics of the information.

\section{Outcomes include:}

a. determines whether information satisfies the research or other information need;

b. uses consciously selected criteria to determine whether the information contradicts or verifies information used from other sources;

c. draws conclusions based upon information gathered;

d. tests theories with discipline-appropriate techniques (e.g., simulators, experiments);

e. determines probable accuracy by questioning the source of the data, the limitations of the information-gathering tools or strategies, and the reasonableness of the conclusions;

f. integrates new information with previous information or knowledge; and

g. selects information that provides evidence for the topic.

5. The information literate student determines whether the new knowledge has an impact on the individual's value system and takes steps to reconcile differences.

Outcomes include:

a. investigates differing viewpoints encountered in the literature; and

b. determines whether to incorporate or reject viewpoints encountered.

6. The information literate student validates understanding and interpretation of the information through discourse with other individuals, subject-area experts, and/or practitioners.

\section{Outcomes include:}

a. participates in classroom and other discussions;

b. participates in class-sponsored electronic communication forums designed to encourage discourse on the topic (e.g., e-mail, bulletin boards, chat rooms); and

c. seeks expert opinion through a variety of mechanisms (e.g., interviews, e-mail, electronic discussion lists).

7. The information literate student determines whether the initial query should be revised.

\section{Outcomes include:}

a. determines if original information need has been satisfied or if additional information is needed; 
b. reviews search strategy and incorporates additional concepts as necessary; and

c. reviews information retrieval sources used and expands to include others as needed.

\section{Standard four}

The information literate student, individually or as a member of a group, uses information effectively to accomplish a specific purpose.

\section{Performance Indicators}

1. The information literate student applies new and prior information to the planning and creation of a particular product or performance.

Outcomes include.

a. organizes the content in a manner that supports the purposes and format of the product or performance (e.g., outlines, drafts, storyboards);

b. articulates knowledge and skills transferred from prior experiences to planning and creating the product or performance;

c. integrates the new and prior information, including quotations and paraphrasings, in a manner that supports the purposes of the product or performance; and

d. manipulates digital text, images, and data, as needed, transferring them from their original locations and formats to a new context.

2. The information literate student revises the development process for the product or performance.

\section{Outcomes include:}

a. maintains a journal or log of activities related to the information seeking, evaluating, and communicating process; and

b. reflects on past successes, failures, and alternative strategies.

3. The information literate student communicates the product or performance effectively to others.

\section{Outcomes include:}

a. chooses a communication medium and format that best supports the purposes of the product or performance and the intended audience;

b. uses a range of information technology applications in creating the product or performance;

c. incorporates principles of design and communication; and d. communicates clearly and with a style that supports the purposes of the intended audience.

\section{Standard five}

The information literate student understands many of the economic, legal, and social issues surrounding the use of information and accesses and uses information ethically and legally.

\section{Performance Indicators}

1. The information literate student understands many of the ethical, legal, and socioeconomic issues surrounding information and information technology.

Outcomes include:

a. identifies and discusses issues related to privacy and security in both the print and electronic environments;

b. identifies and discusses issues related to free vs. fee-based access to information;

c. identifies and discusses issues related to censorship and freedom of speech; and

d. demonstrates an understanding of intellectual property, copyright, and fair use of copyrighted material.

2. The information literate student follows laws, regulations, institutional policies, and etiquette related to the access and use of information resources.

Outcomes include:

a. participates in electronic discussions following accepted practices (e.g., "netiquette");

b. uses approved passwords and other forms of ID for access to information resources;

c. complies with institutional policies on access to information resources;

d. preserves the integrity of information resources, equipment, systems, and facilities;

e. legally obtains, stores, and disseminates text, data, images, or sounds;

f. demonstrates an understanding of what constitutes plagiarism and does not represent work attributable to others as his/her own; and

g. demonstrates an understanding of institutional policies related to human subjects research.

3. The information literate student acknowledges the use of information sources in communicating the product or performance.

Outcomes include:

a. selects an appropriate documentation 
style and uses it consistently to cite sources; and

b. posts permission granted notices, as needed, for copyrighted material.

\section{Appendix I: Selected information literacy initiatives}

- In 1989 the ALA Presidential Committee on Information Literacy issued a Final Report, which defined four components of information literacy: the ability to recognize when information is needed and to locate, evaluate, and use effectively the needed information. http://www.ala.org/acrl/nili/ilit1st.html.

- In 1990, the National Forum on Information Literacy (NFIL) was founded as a response to the recommendations of the ALA Presidential Committee Final Report. NFIL is a "coalition of over 75 education, business, and governmental organizations working to promote international and national awareness of the need for information literacy and encouraging activities leading to its acquisition." Forum members promote information literacy nationally, internationally, and within their own programs. http://www.infolit.org/index.html.

- In March 1998 NFIL issued A Progress Report on Information Literacy: An Update on the American Library Association Presidential Committee on Information Literacy: Final Report. http://www.infolit.org/documents/ progress.html.

- In 1998 the American Association of School Libraries (AASL) and the Association of Educational Communications and Technology
(AECT) published Information Literacy Standards for Student Learning. The AASL/AECT standards detail competencies for students in $\mathrm{K}-12$.

- Since 1989 , in the absence of national standards, many states, school districts, state university systems, and local institutions have developed information literacy competency standards. http://www.fiu.edu/ library/ili/ iliweb.html.

\section{Notes}

1. American Library Association. Presidential Committee on Information Literacy. Final Report. (Chicago: American Library Association, 1989). http://www.ala.org/acrl/nili/ilit1st.html.

2. National Research Council. Commission on Physical Sciences, Mathematics, and Applications. Committee on Information Technology Literacy, Computer Science and Telecommunications Board. Being Fluent with Information Technology. (Washington, D.C.: National Academy Press, 1999). http:// www.nap.edu/readingroom/books/BeFIT/.

3. Several key accrediting agencies concerned with information literacy are the Middle States Commission on Higher Education (MSCHE), the Western Association of Schools and College (WASC), and the Southern Association of Colleges and Schools (SACS).

4. Boyer Commission on Educating Undergraduates in the Research University. Reinventing Undergraduate Education: A Blueprint for America's Research Universities. http:// notes.cc.sunysb.edu/Pres/boyer.nsf/.

\section{Letter to the editor-Need to enforce standards}

I work with groups that accredit occupational therapists, physical therapists, nurses, lawyers, etc. In these cases, each accrediting group has standards. If you don't meet the standards, you are evaluated, warned, and if the situation isn't corrected, you have your accreditation removed-or you don't get it in the first place.

Is academic librarianship professional enough to establish standards, evaluate institutions according to those standards, and then censure institutions that don't meet the standards? Do we have guts enough? I think not-but we should.
We really must establish standards, maybe sliding standards based on faculty and student populations, the total budget of the institution, etc. Then we must establish procedures to examine our member institutions, judge their adherence to the standards, and take appropriate action if the standards are not met.

Are we professionals —or aren't we? As a former English professor I am amazed at how cautious and seemingly scared professional librarians seem to be-David M. Harralson, associate dean and director of the library, Utica College of Syracuse University 